\title{
Antioxidant Activity and Fatty Acid Composition of Four Different Persimmon Seeds
}

\author{
In-Cheol JANG ${ }^{1}$, Eun-Kyung Jo ${ }^{1}$, Sung-Mun BAE ${ }^{1}$, Myoung-Sook BAE ${ }^{1}$, Hyun-Jung LeE ${ }^{2}$, Eunju PARK ${ }^{2}$, \\ Hyun-Gyun YuK $^{3}$, Gwang-Hwan AhN ${ }^{4}$ and Seung-Cheol LeE ${ }^{1 *}$ \\ ${ }^{1}$ Department of Food Science and Biotechnology, Kyungnam University, Masan 631-701, Republic of Korea \\ ${ }^{2}$ Department of Food and Nutrition, Kyungnam University, Masan 631-701, Republic of Korea \\ ${ }^{3}$ Food Science and Technology Programme, Department of Chemistry, National University of Singapore, Science Drive, Singapore 117543, \\ Republic of Singapore \\ ${ }^{4}$ Sweet Persimmon Research Institute, Gyungsangnamdo Agricultural Research \& Extension Services, Gimhae 621-802, Republic of Korea
}

Received May 27, 2010; Accepted July 26, 2010

This study was conducted to determine antioxidant activities in acetone, ethanol, methanol, and water extracts from the seeds of 4 persimmon cultivars. Antioxidant activities were evaluated on the basis of DPPH (1,1-diphenyl-2-picrylhydrazyl) radical-scavenging activity (RSA), ABTS (2,2-azino-bis [3-ethylbenzothiazoline-6-sulfonic acid]) RSA, and reducing power. Cheongdobansi seed extracts showed significantly higher antioxidant activities and phenolic contents than did Bongok, Fuyu, and Nishimurawase seed extracts. Ethanol was more effective for the extraction of antioxidant compounds from persimmons than other solvents. Palmitic acid, oleic acid, and linoleic acid were the main fatty acids found in persimmon seeds. Fuyu seeds contained the highest levels of fatty acids, and the unsaturated fatty acid contents of persimmon seeds range from $\mathbf{7 0 . 4 \%}$ to $\mathbf{7 8 . 3 \%}$. All persimmon seed extracts, with the exception of the water extract of Nishimurawase seeds, inhibited DNA damage induced by $\mathrm{H}_{2} \mathrm{O}_{2}$.

Keywords: persimmon extract, antioxidant activities, antigenotoxic effect, persimmon seed

\section{Introduction}

Persimmons (Diospyros kaki THUNB) are widely cultivated in East Asia, and in part of Europe such as Spain and Israel. Persimmon fruit is known to contain many bioactive compounds including polyphenols and carotenoids, as well as dietary fiber and minerals (New Food Composition Table Editing Committee, 2009). Traditionally, persimmons have been used for their medicinal properties, such as their blood pressure-lowering and diuretic effects. They have been used to treat coughs and the seeds used for stopping hiccups (Steinmetz and Potter, 1996). Persimmons are believed to ameliorate degenerative human diseases. The main health and medicinal benefits of persimmons result from the antioxidant activity of high-molecular-weight tannin and ascorbic acid.

There are many reports on the antioxidant activity of the fruit, leaf, and peel of persimmons (Fukai et al., 2009; Lee et al., 2008; Tsurunaga et al., 2008; Jung et al., 2005). Stud-

*To whom correspondence should be addressed.

E-mail: sclee@kyungnam.ac.kr ies of the antioxidant activity of persimmon seeds have been carried out (Ahn et al., 2002; Cantrell et al., 2003; Jang et al., 2010); however, few studies have compared the functional activity of seeds of different persimmon cultivars. In Korea, not only is raw persimmon fruit consumed, many processed goods such as dried fruit, vinegar, and wine have been produced from the persimmon fruit. Persimmon seeds are considered to be byproducts in persimmon fruit processing.

There are 2 types of persimmon cultivars: astringent and non-astringent (or sweet). Bongok and Cheongdobansi cultivars are astringent persimmons, and Fuyu and Nishimurawase cultivars are non-astringent. Bongok originated from the Japanese persimmon (Diospyros kaki 'Hachiya') (Cho et al., 2007) and is widely consumed in both its natural and dried forms. Cheongdobansi was named for the region in which it was cultivated and for its flat shape (in Korean language, Cheongdobansi means a flat shaped persimmon of Cheongdo region), and was highly popular because of its physiological activity. Fuyu is the most widely cultivated non-astringent persimmon in Korea. Nishimurawase is an 
early-harvest, non-astringent persimmon, which is thus widely consumed during the mid-autumn Korean Chuseok holiday.

There is little information on the antioxidant activity and fatty acid profile of persimmon seeds. In this study, seeds from the 4 popular Korean persimmons were collected, and their antioxidant activity and fatty acid composition were evaluated.

\section{Materials and Methods}

Materials Persimmon seeds were provided by the Sweet Persimmon Research Institute (Gimhae, Korea). LAscorbic acid (vitamin C); 2,2-azino-bis (3-ethylbenzothiazoline-6-sulfonic acid) diammonium salt (ABTS); butylated hydroxytoluene (BHT); dimethyl sulfoxide (DMSO); trichloroacetic acid (TCA); 1,1-diphenyl-2-picrylhydrazyl (DPPH); and boron trifluoride methanol solution $14 \%\left(\mathrm{BF}_{3}\right)$ were purchased from the Sigma Chemical Co., as were hydrogen peroxide, potassium chloride, potassium ferricyanide, and potassium phosphate. Folin-Ciocalteu reagents were obtained from Wako Pure Chemical Industries Ltd. All other organic solvents and chemicals used in this study were of analytical grade.

Preparation of extracts from persimmon seeds The seeds of 4 different types of fresh persimmon were used: Bongok (BS), Cheongdobansi (CS), Fuyu (FS), and Nishimurawase (NS). The seeds of each were freeze-dried in a freeze dryer (Ilshin Lab., Seoul, Korea). A mill (MC 811C, Novita Co., Seoul, Korea) was used to grind the dried persimmon seeds, and they were then passed through a 25 -mesh sieve. Each type of seed powder $(5 \mathrm{~g})$ was extracted with $100 \mathrm{~mL}$ of 4 different solvents (acetone, ethanol, methanol, and water) overnight at room temperature and filtered through a Whatman no. 1 filter paper. The solvents were then removed by evaporation in vacuo, and dried extracts were obtained. Each dried extract was re-dissolved in DMSO at a concentration of $50 \mathrm{mg} / \mathrm{mL}$, and diluted with DMSO as needed. All samples were placed in a glass bottle and stored at $4^{\circ} \mathrm{C}$ until required. The extraction yield was calculated using the following formula:

\section{Extraction yield $(\%)=$}

[dried extract weight/dried sample weight] $\times 100$

DPPH radical-scavenging activity The DPPH radicalscavenging activity (RSA) of each extract was determined according to the method described by (Jeong et al., 2004). An aliquot $(0.1 \mathrm{~mL})$ of extract was dissolved in DMSO and mixed with $0.9 \mathrm{~mL}$ of $0.041 \mathrm{mM}$ DPPH in ethanol for 30 min. By using a spectrophotometer (Shimadzu UV-1601, Kyoto, Japan), the optical density (OD) of the sample was measured at $517 \mathrm{~nm}$. RSA was expressed as the percentage inhibition and calculated using the following formula:

$$
\text { DPPH RSA }(\%)=[1-(\text { sample OD/control OD })] \times 100
$$

ABTS RSA The ABTS RSA was evaluated using the method described by (Muller, 1985). Each extract $(0.1 \mathrm{~mL})$ was mixed with potassium phosphate buffer $(0.1 \mathrm{~mL}, 0.1 \mathrm{M}$, pH 5.0) and hydrogen peroxide $(20 \mu \mathrm{L}, 10 \mathrm{mM})$, and preincubated at $37^{\circ} \mathrm{C}$ for $5 \mathrm{~min}$. After pre-incubation, ABTS ( 30 $\mu \mathrm{L}, 1.25 \mathrm{mM})$ in phosphate-citrate buffer (0.05 M, pH 5.0), and peroxidase ( $30 \mu \mathrm{L}, 1 \mathrm{unit} / \mathrm{mL}$ ) were added to the mixture and it was then incubated at $37^{\circ} \mathrm{C}$ for $10 \mathrm{~min}$. A multiplate reader (Sunrise RC/TS /TS Color-TC/TW/BC/6 Filter, Tecan Austria GmbH, Grödig, Austria) was used to determine OD level at $405 \mathrm{~nm}$. The ABTS RSA was calculated using the following formula:

$$
\operatorname{ABTS} \operatorname{RSA}(\%)=[1-(\text { sample OD/control OD })] \times 100
$$

Reducing power The reducing power (RP) of each extract was determined according to the method described by (Oyaizu, 1986). The extract (1.0 mL), sodium phosphate buffer (1.0 mL, $0.2 \mathrm{M}, \mathrm{pH} 6.6)$, and potassium ferricyanide (1.0 $\mathrm{mL}, 10 \mathrm{mg} / \mathrm{mL}$ ) were mixed together and incubated at $50^{\circ} \mathrm{C}$ for $20 \mathrm{~min}$. Trichloroacetic acid $(1.0 \mathrm{~mL}, 100 \mathrm{mg} / \mathrm{mL})$ was added and the mixture centrifuged at $13,400 \times g$ for $5 \mathrm{~min}$. The supernatant $(1.0 \mathrm{~mL})$ was mixed with distilled water $(1.0$ $\mathrm{mL})$ and ferric chloride $(0.1 \mathrm{~mL}, 1.0 \mathrm{mg} / \mathrm{mL})$, and its OD was measured at $700 \mathrm{~nm}$.

Total phenolic content The total phenolic content (TPC) of each extract was determined according to the method described by (Gutfinger, 1981). Each extract $(1.0 \mathrm{~mL})$ at a concentration of $1 \mathrm{mg} / \mathrm{mL}$, was mixed with $1.0 \mathrm{~mL}$ of $2 \%$ $\mathrm{Na}_{2} \mathrm{CO}_{3}$ after standing for $3 \mathrm{~min}$. Subsequently, $0.2 \mathrm{~mL}$ of $50 \%$ Folin-Ciocalteu reagent was added to the mixture after it was left to stand for $30 \mathrm{~min}$. The mixture was centrifuged at $13,400 \times g$ for $5 \mathrm{~min}$, and its OD was measured at $750 \mathrm{~nm}$. TPCs were expressed as gallic acid equivalents.

Fatty acid analysis Each persimmon seed was dried in a freeze-dryer and was then ground in a mill (Ilshin Lab., Seoul, Korea). The grounds were passed through a 25 -mesh sieve. Each $5 \mathrm{~g}$ of the resulting seed powder was extracted with $50 \mathrm{~mL}$ of ether in a flask, over $24 \mathrm{~h}$ at room temperature, and filtered through Whatman no. 3 filter paper. Ether in the flask was then removed by evaporation in vacuo and the result was a lipid extract. For saponification, $5 \mathrm{~mL}$ of $0.5 \mathrm{~N}$ $\mathrm{NaOH} / \mathrm{MeOH}$ were added to the flask and it was heated in a heating mantle at $110^{\circ} \mathrm{C}$ for $10 \mathrm{~min}$. We added $3 \mathrm{~mL}$ of $14 \%$ $\mathrm{BF}_{3}$ to the liberated fatty acids and continuously heated for $2 \mathrm{~min}$, then $5 \mathrm{~mL}$ of hexane were added and the mixture was heated for a further $1 \mathrm{~min}$. After the addition of $15 \mathrm{~mL}$ of 
saturated $\mathrm{NaCl}$ solution, the mixture was vigorously shaken for $10 \mathrm{~s}$. The hexane layer was removed and dehydrated by passing through a Pasteur pipette packing $\mathrm{Na}_{2} \mathrm{~S}_{2} \mathrm{O}_{5}$. The solvent was evaporated on a rotary evaporator. After adding 5 $\mathrm{mL}$ hexane to resolve the residues into sample, a $5 \mu \mathrm{L}$ aliquot of each sample was subsequently analyzed by gas chromatography (Agilent GC6890, Agilent Technologies, USA). A HP INNOWAX column (Crosslinked polyethylene glycol, $30 \mathrm{~m} \times 0.25 \mathrm{~mm}$ ID $\times 0.25 \mu \mathrm{m})$ from Agilent Technologies (Folsom, CA, USA) was used. $\mathrm{N}_{2}$ was used as carrier gas at a flow rate of $1.0 \mathrm{~mL} / \mathrm{min}$. Oven temperature was programmed from 150 to $180^{\circ} \mathrm{C}$ at a rate of $20^{\circ} \mathrm{C} / \mathrm{min}$ with initial and final hold times of 1 and $2 \mathrm{~min}$, respectively. Then, temperature was increased to $230^{\circ} \mathrm{C}$ at $3{ }^{\circ} \mathrm{C} / \mathrm{min}$ with holding time of 5 min, and finally to $250^{\circ} \mathrm{C}$ at $5^{\circ} \mathrm{C} / \mathrm{min}$ with $5 \mathrm{~min}$ of holding. Injection and flame ionization detector (FID) temperatures were maintained at $250^{\circ} \mathrm{C}$. Standard methyl ester fatty acids (Alltech Co., Deerfield, IL, USA) were used for the quantitative analysis.

DNA damage by alkaline comet assay Leukocytes were isolated as a fraction of mononuclear cells (containing lymphocytes and monocytes) from anonymous buffy coat preserves by gradient centrifugation with HISTOPAQUE ${ }^{\circledR}-1077$ (Sigma, St. Louis, MO, USA). Leukocytes were incubated with each extract in DMSO $(50 \mu \mathrm{g} / \mathrm{mL})$ at $37^{\circ} \mathrm{C}$ for $30 \mathrm{~min}$ in a dark incubator. In order to provide an oxidative stimulus, they were then resuspended in PBS with $200 \mu \mathrm{M} \mathrm{H}_{2} \mathrm{O}_{2}$ for 5 min on ice. After each treatment, samples were centrifuged at $250 \times g$ for $5 \mathrm{~min}$ and washed with PBS. DMSO (1\%), without an oxidative stimulus, was treated as a negative control. The leukocytes were then mixed with $75 \mu \mathrm{L}$ of $0.7 \%$ lowmelting agarose, and added to slides pre-coated with $0.5 \%$ agarose. The slides were then immersed in lysis solution (2.5 $\mathrm{M} \mathrm{NaCl}, 100 \mathrm{mM}$ EDTA, $10 \mathrm{mM}$ Tris, and 1\% sodium laurylasarcosine; $1 \%$ Triton X-100 and 10\% DMSO) for $1 \mathrm{~h}$ at $4{ }^{\circ} \mathrm{C}$. For $40 \mathrm{~min}$, the slides were immersed in an electrophoresis tank containing $300 \mathrm{mM} \mathrm{NaOH}$ and $10 \mathrm{mM} \mathrm{Na}_{2}$ EDTA (pH 13.0). For electrophoresis of the DNA, an electric current of $25 \mathrm{~V} / 300 \pm 3 \mathrm{~mA}$ was applied for $20 \mathrm{~min}$ at $4^{\circ} \mathrm{C}$. The slides were washed 3 times with a neutralizing buffer $(0.4 \mathrm{M}$ Tris, $\mathrm{pH}$ 7.5) for $5 \mathrm{~min}$ at $4^{\circ} \mathrm{C}$, and then treated with ethanol for another $5 \mathrm{~min}$ before staining with $50 \mu \mathrm{L}$ of ethidium bromide $(20 \mu \mathrm{g} / \mathrm{mL})$. In order to determine the percentage of fluorescence in the tail (tail intensity [TI]; 50 cells from each of 2 replicate slides), measurements were carried out using an image analyzer (Kinetic Imaging Ltd., Komet 4.0, Merseyside, UK) and a fluorescence microscope (Leica DMLB, Wetzlar, Germany).

Statistical analysis All measurements were performed in triplicate, and the SPSS package for Windows (Ver. 12) was used for the analyses of variance. The mean values (TI) of the DNA damage in each treatment were compared using a one-way analysis of variance (ANOVA), followed by Duncan's multiple range test. A p-value less than 0.05 was considered statistically significant.

\section{Results and Discussion}

Extraction yields The extraction yields of 4 different persimmon seeds are presented in Table 1. Relatively higher extraction yields were obtained from CS than from other persimmon seeds. The highest extraction yield was obtained from the CS methanol extract (11.17\%), and the lowest extraction yield was obtained from the BS water extract (1.98\%). These results showed that the extraction yield varied according to the solvent and the variety of persimmon seed, indicating that the seeds vary in their components.

DPPH RSA Investigating the scavenging capacity of the DPPH free radical is a common method of evaluating the antioxidative activity of antioxidants. The DPPH RSA of extracts from various persimmon seeds were evaluated by comparison with ascorbic acid and BHT, which are well-known natural and synthetic antioxidants, respectively. As shown in Table 2, extracts from methanol, ethanol, and acetone seeds had a relatively strong DPPH RSA (low $\mathrm{IC}_{50}$ value), exhibiting a high antioxidant capacity compared to water extracts. Acetone and ethanol extracts of CS showed the lowest $\mathrm{IC}_{50}$ values of 34.5 and $37.2 \mu \mathrm{g} / \mathrm{mL}$, which were only 1.28 - to 1.38 -fold lower than those of vitamin $\mathrm{C}\left(\mathrm{IC}_{50}=26.9 \mu \mathrm{g} /\right.$ $\mathrm{mL}$ ) and 8.34- to 8.99-fold higher than those of BHT (IC50 $=310.2 \mu \mathrm{g} / \mathrm{mL}$ ). Most solvents, with the exception of water, were effective in the extraction of antioxidants from BS, CS, FS, and NS. Persimmon seed extract showed a higher DPPH RSA than did grape seed extract (Ahn et al., 2002), and Jang et al. (Jang et al., 2010) reported that the persimmon seed extract showed significantly higher DPPH RSA than that of the calyx, peel, and flesh. This might be due to differences in: 1) the amount and the form of tannin, which is the main

Table 1. Extraction yields from different persimmon seeds by solvents.

(Unit: \%)

\begin{tabular}{ccccc}
\hline & \multicolumn{4}{c}{ Persimmon seeds } \\
\cline { 2 - 5 } Solvents & BS & CS & FS & NS \\
\hline Methanol & 7.00 & 11.17 & 7.87 & 8.01 \\
Ethanol & 4.07 & 9.25 & 6.80 & 6.25 \\
Acetone & 10.00 & 10.32 & 2.02 & 2.37 \\
Water & 1.98 & 6.69 & 9.12 & 9.62 \\
\hline
\end{tabular}

BS: Bongok Cultivar's seed

CS: Cheongdobansi Cultivar's seed

FS: Fuyu Cultivar's seed

NS: Nishimurawase Cultivar's seed 
Table 2. DPPH radical-scavenging activity of extracts from different persimmon seeds by solvents.

(Unit: $\mathrm{IC}_{50}[\mu \mathrm{g} / \mathrm{mL}]^{1)}$ )

\begin{tabular}{|c|c|c|c|c|c|c|}
\hline \multirow[b]{2}{*}{ Solvents } & \multicolumn{4}{|c|}{ Persimmon seeds } & \multicolumn{2}{|c|}{ Positive controls } \\
\hline & $\mathrm{BS}$ & $\mathrm{CS}$ & FS & NS & Vit-C & BHT \\
\hline Methanol & $82.1 \pm 0.8^{\mathrm{dy}}$ & $38.6 \pm 0.5^{\mathrm{az}}$ & $68.9 \pm 0.5^{\mathrm{cz}}$ & $49.0 \pm 0.6^{\mathrm{bz}}$ & \multirow{4}{*}{$26.9 \pm 0.2$} & \multirow{4}{*}{$310.2 \pm 4.0$} \\
\hline Ethanol & $50.4 \pm 2.1^{\mathrm{cz}}$ & $37.2 \pm 0.5^{\mathrm{az}}$ & $47.9 \pm 0.7^{\mathrm{bz}}$ & $45.0 \pm 1.0^{\mathrm{bz}}$ & & \\
\hline Acetone & $79.1 \pm 0.7^{\mathrm{dy}}$ & $34.5 \pm 0.6^{\mathrm{az}}$ & $61.2 \pm 1.6^{\mathrm{bz}}$ & $75.0 \pm 1.6^{\mathrm{cz}}$ & & \\
\hline Water & $1,605.2 \pm 11.3^{\mathrm{dx}}$ & $318.0 \pm 5.0^{\mathrm{ay}}$ & $1,354.6 \pm 22.3^{\mathrm{cy}}$ & $1,252.1 \pm 152.3^{\text {by }}$ & & \\
\hline
\end{tabular}

${ }^{1)} \mathrm{IC}_{50}(\mu \mathrm{g} / \mathrm{mL})$ : Concentration for scavenging $50 \%$ of DPPH radicals.

BS, Bongok Cultivar's seed; CS, Cheongdobansi Cultivar's seed; FS, Fuyu Cultivar's seed; NS, Nishimurawase Cultivar's seed.

All measurements were done in triplicate, and all values are means \pm standard deviation.

Different letters within a row (a-d) and column (w-z) are significantly different $(\mathrm{p}<0.05), \mathrm{n}=3$.

Table 3. ABTS radical-scavenging activity of extracts from different persimmon seeds by solvents.

\begin{tabular}{|c|c|c|c|c|c|c|}
\hline \multirow[b]{2}{*}{ Solvents } & \multicolumn{4}{|c|}{ Persimmon seeds } & \multicolumn{2}{|c|}{ Positive controls } \\
\hline & BS & $\mathrm{CS}$ & FS & NS & Vit-C & BHT \\
\hline Methanol & $37.4 \pm 0.2^{\mathrm{cz}}$ & $24.4 \pm 1.7^{\mathrm{az}}$ & $29.4 \pm 1.0^{\mathrm{bz}}$ & $84.0 \pm 5.8^{\mathrm{dz}}$ & \multirow{4}{*}{$18.8 \pm 0.6$} & \multirow{4}{*}{$15.8 \pm 1.1$} \\
\hline Ethanol & $29.2 \pm 0.8^{\mathrm{abz}}$ & $22.7 \pm 0.8^{\mathrm{az}}$ & $36.6 \pm 0.6^{\mathrm{bz}}$ & $65.5 \pm 3.1^{\mathrm{cz}}$ & & \\
\hline Acetone & $43.5 \pm 4.0^{\mathrm{cz}}$ & $12.4 \pm 0.1^{\mathrm{az}}$ & $34.86 \pm 2.1^{\mathrm{bz}}$ & $84.6 \pm 1.7^{\mathrm{dz}}$ & & \\
\hline Water & $974.2 \pm 23.9^{\text {cy }}$ & $106.5 \pm 5.5^{\mathrm{ay}}$ & $1,055.77 \pm 18.65^{\mathrm{dy}}$ & $456.3 \pm 11.0^{\text {by }}$ & & \\
\hline
\end{tabular}

${ }^{1)} \mathrm{IC}_{50}(\mu \mathrm{g} / \mathrm{mL})$ : Concentration for scavenging $50 \%$ of ABTS radicals.

BS, Bongok Cultivar's seed; CS, Cheongdobansi Cultivar's seed; FS, Fuyu Cultivar's seed; NS, Nishimurawase Cultivar's seed.

All measurements were done in triplicate, and all values are means \pm standard deviation.

Different letters within a row (a-d) and column (w-z) are significantly different $(\mathrm{p}<0.05), \mathrm{n}=3$.

phenolic compound of persimmon fruit (Gu et al., 2008); 2) the amount of antioxidant carotenoid compound (Veberic et al., 2010); and 3) the amount of vitamin C (Hosotani et al., 2004).

ABTS RSA Similar to the results of the DPPH RSA, CS extracts showed higher ABTS RSA than other seeds (Table 3). The highest ABTS RSA was detected in the CS acetone extract $\left(\mathrm{IC}_{50}=12.4 \mu \mathrm{g} / \mathrm{mL}\right)$, exhibiting superior RSA when compared with ascorbic acid and BHT $\left(\mathrm{IC}_{50}=18.8\right.$ and 15.8 $\mu \mathrm{g} / \mathrm{mL}$, respectively). The ABTS method is suitable for the monitoring of lipophilic antioxidants such as carotenoids, and the lipophilic extracts of nutritional components (Nicoletta et al., 1999). This fact may explain why water (the most polar solvent) extracts from persimmon seeds exhibited the lowest ABTS RSA when compared with other solvent extracts.

$R P \quad$ The antioxidant ability of certain compounds is associated with their RP (Jayaprakasha et al., 2001), thus the RP may serve as a significant indicator of potential antioxidant activity (Meir et al., 1995). RP was determined by measuring the reduction of the $\mathrm{Fe}^{3+}$ form of $\mathrm{Fe}^{3+} /$ ferricyanide complexes to the ferrous $\left(\mathrm{Fe}^{2+}\right)$ form. The RP of extracts was evaluated and listed in Table 4. CS extracts showed a significantly higher RP $(\mathrm{p}<0.05)$ than that of other seeds, regardless of the extraction solvents used. The acetone extract from CS had the highest RP $\left(\mathrm{IC}_{50}=48.8 \mu \mathrm{g} / \mathrm{mL}\right)$, and the water extract from FS produced the lowest $\mathrm{RP}\left(\mathrm{IC}_{50}=1,389.0 \mu \mathrm{g} /\right.$ $\mathrm{mL}$ ). With regard to antioxidant activity, the overall trend was very similar to those already described.

TPC Table 5 shows the TPC of each extract at a concentration of $1 \mathrm{mg} / \mathrm{mL}$. Extracts from CS seeds revealed a significantly higher $(p<0.05)$ TPC than did extracts from other persimmon seeds. The highest TPC was found in an acetone extract from CS at 3,008.0 $\mu \mathrm{M} \mathrm{GAE} / \mathrm{g}$. This result was probably due to a high amount of antioxidant compounds, including phenolic compounds such as tannin (Gorinstein et al., 1994). Acetone was the most effective solvent for the extraction of phenolics from FS and CS, whereas ethanol extracts showed the highest TPC in NS and BS. The order of the TPC of extracts from the 4 different persimmon seeds al- 
Table 4. Reducing power of extracts from different persimmon seeds by solvent.

(Unit: $\left.\mathrm{IC}_{50}[\mu \mathrm{g} / \mathrm{mL}]^{1)}\right)$

\begin{tabular}{|c|c|c|c|c|c|c|}
\hline \multirow[b]{2}{*}{ Solvents } & \multicolumn{4}{|c|}{ Persimmon seeds } & \multicolumn{2}{|c|}{ Positive controls } \\
\hline & $\mathrm{BS}$ & $\mathrm{CS}$ & FS & NS & Vit-C & BHT \\
\hline Methanol & $173.3 \pm 5.8^{\mathrm{cy}}$ & $55.2 \pm 0.5^{\mathrm{az}}$ & $84.4 \pm 0.7^{\text {by }}$ & $86.6 \pm 0.8^{\mathrm{bz}}$ & \multirow{4}{*}{$24.0 \pm 0.2$} & \multirow{4}{*}{$52.3 \pm 0.2$} \\
\hline Ethanol & $80.7 \pm 0.7^{\mathrm{cz}}$ & $54.5 \pm 0.7^{\mathrm{az}}$ & $72.4 \pm 0.4^{\mathrm{bz}}$ & $81.5 \pm 0.6^{\mathrm{cz}}$ & & \\
\hline Acetone & $182.1 \pm 5.0^{\mathrm{cy}}$ & $48.8 \pm 0.3^{\mathrm{az}}$ & $88.9 \pm 0.5^{\text {by }}$ & $206.3 \pm 3.6^{\mathrm{dy}}$ & & \\
\hline Water & $884.6 \pm 2.6^{\mathrm{cx}}$ & $287.0 \pm 11.7^{\text {ay }}$ & $1,389.0 \pm 9.6^{\mathrm{dx}}$ & $721.0 \pm 54.3^{\mathrm{bx}}$ & & \\
\hline
\end{tabular}

${ }^{1)} \mathrm{IC}_{50}(\mu \mathrm{g} / \mathrm{mL})$ : Concentration for increasing 0.500 value in optical density.

BS, Bongok Cultivar's seed; CS, Cheongdobansi Cultivar's seed; FS, Fuyu Cultivar's seed; NS, Nishimurawase Cultivar's seed.

All measurements were done in triplicate, and all values are means \pm standard deviation.

Different letters within a row (a-d) and column (w-z) are significantly different $(\mathrm{p}<0.05), \mathrm{n}=3$.

Table 5. Total phenolic contents of extracts from different persimmon seeds by solvents.

(Unit: $\mu \mathrm{M}$ GAE)

\begin{tabular}{ccccc}
\hline & \multicolumn{3}{c}{ Persimmon seeds } \\
\cline { 2 - 5 } Solvents & BS & CS & FS & NS \\
\hline Methanol & $1,196.8 \pm 2.2^{\text {ay }}$ & $2,607.0 \pm 12.1^{\text {cy }}$ & $1,772.6 \pm 18.8^{\text {by }}$ & $1,660.1 \pm 49.4^{\text {bx }}$ \\
Ethanol & $1,822.7 \pm 8.2^{\text {bw }}$ & $2,884.0 \pm 67.3^{\text {dx }}$ & $1,879.2 \pm 9.4^{\mathrm{cx}}$ & $1,734.4 \pm 24.5^{\text {aw }}$ \\
Acetone & $1,598.3 \pm 23.9^{\text {ax }}$ & $3,008.0 \pm 55.7^{\text {cx }}$ & $2,122.4 \pm 7.5^{\text {bw }}$ & $1,536.1 \pm 31.2^{\text {ay }}$ \\
Water & $203.1 \pm 11.6^{\text {az }}$ & $632.6 \pm 26.9^{\text {cz }}$ & $188.2 \pm 9.0^{\text {az }}$ & $352.7 \pm 5.9^{\text {bz }}$ \\
\hline
\end{tabular}

${ }^{1)}$ GAE: gallic acid equivalents.

BS, Bongok Cultivar's seed; CS, Cheongdobansi Cultivar's seed; FS, Fuyu Cultivar's seed; NS, Nishimurawase Cultivar's seed.

All measurements were done in triplicate, and all values are means \pm standard deviation.

Different letters within a row (a-d) and column (w-z) are significantly different $(\mathrm{p}<0.05), \mathrm{n}=3$.

most coincided with that of their antioxidant activity, indicating that there was a correlation between the TPC and other antioxidant properties of the extracts.

Astringent persimmon pulp contains higher amount of phenolics than non-astringent ones (Suzuki et al., 2005), because its pulp contain an astringent substance, tannin, and the soluble tannin concentration is high at maturity (Macheix et al., 1990). Pulps of astringent persimmons (BS and CS) in this study also showed higher TPC than those of nonastringent ones (FS and NS) (data not shown), however, TPC in the seeds did not show such a trend. It may be a reason because phenolic are second metabolites of plant and seeds cannot metabolite actively.

Protective effect of persimmon on oxidative DNA damage in human leukocytes The genotoxic effects of $\mathrm{H}_{2} \mathrm{O}_{2}$ and the protective ability of each extract were assessed in normal human leukocytes by comet assay (Fig. 1). At a concentration of $50 \mu \mathrm{g} / \mathrm{mL}$, the solvent extracts (methanol, ethanol, and acetone) of BS, CS and FS, the water extract of BS, and the methanol extract of NS exhibited the greatest protective ef- fect on $\mathrm{H}_{2} \mathrm{O}_{2}$-induced DNA damage, showing no significant difference between the extracts and the DMSO-treated negative controls $(\mathrm{p}>0.05)$. The negative control had 9.3\% tail DNA intensity, whereas leukocytes challenged with $200 \mu \mathrm{M}$ of $\mathrm{H}_{2} \mathrm{O}_{2}$ had a value of $43.1 \%$ - indicating extensive DNA damage. However, $50 \mu \mathrm{g} / \mathrm{mL}$ of all extracts of BS and the solvent extracts of CS, FS, and NS significantly inhibited $\mathrm{H}_{2} \mathrm{O}_{2}$-induced DNA damage to cellular DNA, as indicated by the lower average tail DNA intensities of $12.9,8.4,7.1$, and $10.2 \%$, respectively.

Hydrogen peroxide is believed to cause DNA strand breakage by generation of the hydroxyl radical $(\mathrm{OH})$ close to the DNA molecule via the Fenton reaction (Diplock, 1991). Thus, antioxidants have the potential to protect DNA against oxidative damage. Several earlier studies (Fan and Lou, 2004; Kaviarasan et al., 2004; Godevac et al., 2009) demonstrated that phenolic compounds from fruit and vegetable seeds protect against oxygen species-mediated DNA damage. Although there is a little exception, TPC of persimmon seeds in this study also showed strong relationship with their antig- 


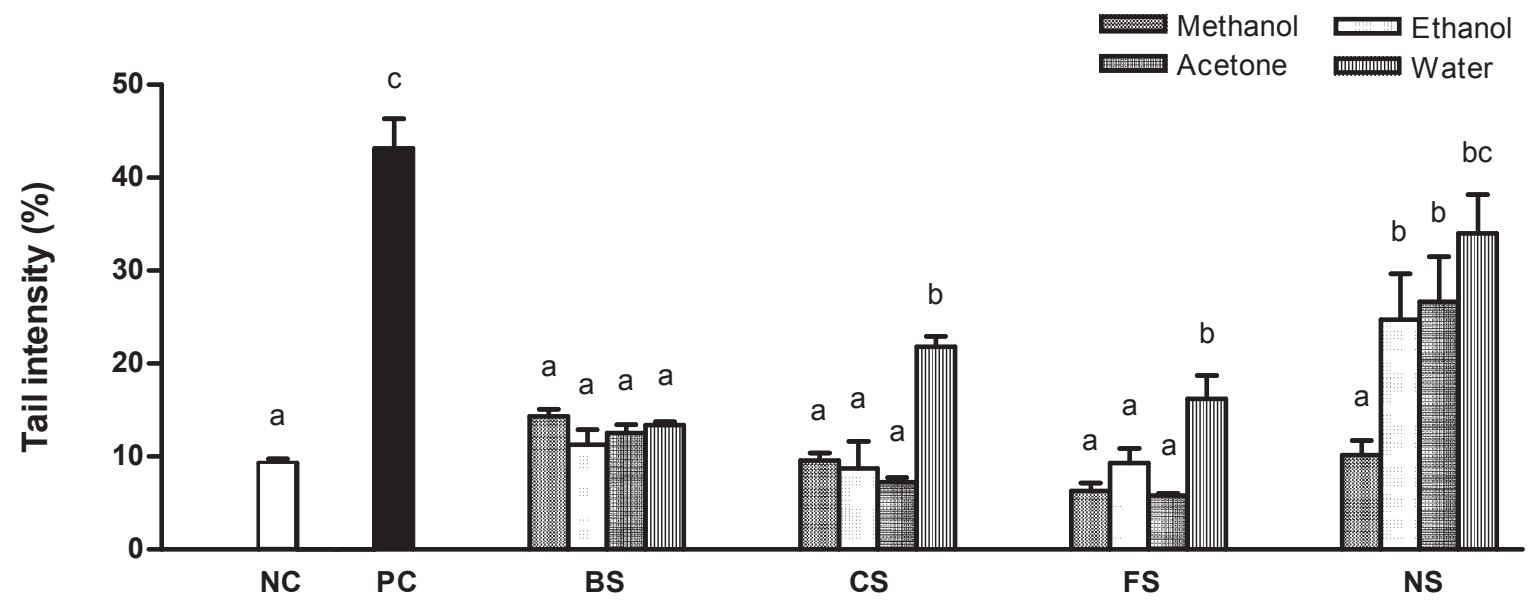

Fig. 1. Effect of persimmon seed powder $(50 \mu \mathrm{g} / \mathrm{mL})$, extracted using methanol, ethanol, acetone, or water, on $200 \mu \mathrm{M}$ $\mathrm{H}_{2} \mathrm{O}_{2}$-induced DNA damage in human leukocytes. Values are means and standard errors of triplicate experiments. NC, $1 \%$ DMSO-treated negative control; PC, $200 \mu \mathrm{M} \mathrm{H}_{2} \mathrm{O}_{2}$-treated positive control. BS, Bongok Cultivar's seed; CS, Cheongdobansi Cultivar's seed; FS, Fuyu Cultivar's seed; NS, Nishimurawase Cultivar's seed. Values with different letters are significantly different from each other $(\mathrm{p}<0.05$; Duncan's multiple range test).

Table 6. Fatty acid analysis of extracts from different persimmon seeds.

(Unit: $\mu \mathrm{g} / \mathrm{g}$ )

\begin{tabular}{ccccccccccccccccc}
\hline & C14:0 & C16:0 & C16:1 & C18:0 & C18:1 & C18:2 & C18:3 & C20:0 & C20:1 & C20:4 & C22:0 & Total & SFA $^{1)}$ & UFA $^{2)}$ \\
\cline { 2 - 13 } BS & 28.1 & 536.3 & 4.1 & 55.7 & 822.3 & 642.8 & n.d & n.d & 3.1 & n.d & n.d & 2092.4 & 29.6 & 70.4 \\
CS & 3.0 & 190.1 & n.d & 8.6 & 269.6 & 261.7 & n.d & n.d & n.d & n.d & n.d & 733.0 & 27.5 & 72.5 \\
FS & 35.5 & 546.2 & 9.1 & 72.8 & 839.4 & 968.6 & n.d & 7.1 & 4.8 & n.d & 31.2 & 2514.7 & 26.3 & 73.7 \\
NS & 18.6 & 387.7 & n.d & 49.8 & 793.7 & 838.3 & n.d & 1.3 & 21.2 & n.d & n.d & 2110.6 & 21.7 & 78.3 \\
\hline
\end{tabular}

${ }^{\mathrm{a}}$ Not detected.

1)SFA: saturated fatty acid.

2)UFA: unsaturated fatty acid.

BS, Bongok Cultivar's seed; CS, Cheongdobansi Cultivar's seed; FS, Fuyu Cultivar's seed; NS, Nishimurawase Cultivar's seed.

enotoxic activity. For example, high TPC in acetone extracts of CS and FS showed strong antigenotoxic activity, while low TPC in water extracts of CS, FS, and NS exhibited week activity.

Fatty acid analysis According to fatty acid analysis (Table 6), palmitic acid (C16:0), oleic acid (C18:1), and linoleic acid (C18:2) are the main fatty acids in persimmon seeds. FS showed the highest level of fatty acid (C16:0 $=546.2 \mu \mathrm{g} /$ g, C18:1 = $839.4 \mu \mathrm{g} / \mathrm{g}, \mathrm{C} 18: 2=968.6 \mu \mathrm{g} / \mathrm{g}$ ). The most common was linoleic acid (an omega- 6 fatty acid), which is the metabolic precursor of eicosanoids. Eicosanoids are a group of biologically important lipids which include prostaglandins, thromboxanes, lipoxins and leukotrienes (Bourre et al., 1993). Linoleic acid has been reported to exhibit significant antioxidant activity (Richard et al., 2008).
Lee and Kim (1994) also reported that palmitic acid, oleic acid, and linoleic acid were the main fatty acids in FS. On the other hand, CS, which showed the highest antioxidant activity, contained the lowest level of fatty acids (C16:0 = $190.1 \mu \mathrm{g} / \mathrm{g}, \mathrm{C} 18: 1=269.6 \mu \mathrm{g} / \mathrm{g}, \mathrm{C} 18: 2=261.7 \mu \mathrm{g} / \mathrm{g})$. Orhan and Sener (2002) identified palmitic acid and stearic acid (C18:0) in persimmon seed oil, but did not detect linoleic acid. In the present study, the percentage of unsaturated fatty acid contents in persimmon seeds ranged from 70.4 to $78.3 \%$. The unsaturated fatty acid contents of the flesh and peel of an astringent persimmon (Gojongsi) were reported as 70.2 and $72.8 \%$, respectively (Moon et al., 1995). The seeds of astringent persimmons (BS, CS) contained lower amounts of unsaturated fatty acids and lower total amounts of fatty acids than those of non-astringent persimmons (FS, NS). 


\section{Conclusion}

This study was the first to compare the differences in the functional activities of persimmon seeds of different cultivars. All persimmon seeds exhibit strong antioxidant activity in vitro, affording significant protection against oxidative DNA damage in human leukocytes. CS extracts exhibited the highest antioxidant activity, regardless of the solvent used. This study also found that ethanol is a powerful solvent for the extraction of antioxidant compounds from persimmon seeds, and this fact supports the use of this solvent in the food and cosmetic industries.

Acknowledgement This study was supported by Sweet Persimmon Export Research Organization of Technology Development Program for Agriculture and Forestry, Ministry of Agriculture, Forestry and Fisheries, Republic of Korea.

\section{References}

Ahn, H.S., Jeon, T.I., Lee, J.Y., Hwang, S.G., Lim, Y. and Park, D.K. (2002). Antioxidative activity of persimmon and grape seed extract: in vitro and in vivo. Nutr. Res., 22, 1265-1273.

Bourre, J.M., Bonneil, M., Clement, M., Dumont, O., Durand, G., Lafont, H., Nalbone, G. and Piciotti, M. (1993). Function of dietary polyunsaturated fatty acids in the nervous system. Prostag. Leukotr. Ess., 48, 5-15.

Cantrell, C.L., Berhow, M.A., Phillips, B.S., Duval, S.M., Weisleder, D. and Vaughn, S.F. (2003). Bioactive crude plant seed extracts from the NCAUR oilseed repository. Phytomedicine, 10, 325-333.

Cho, D.H., Chon, I.J., Kwon, S.T., Song, Y.S. and Chou, Y.D. (2007). Genetic relationships of Korean astringent persimmon varieties using AFLP analysis. J. Korean Soc. Hort. Sci., 25, 114-118.

Diplock, A.T. (1991). Antioxidant nutrients and disease prevention: an overview. Am. J. Clin. Nutr., 53, 189S-193S.

Fan, P. and Lou, H. (2004). Effects of polyphenols from grape seeds on oxidative damage to cellular DNA. Mol. Cell Biochem., 267, 67-74.

Fukai, S., Tanimoto, S., Maeda, A., Fukuda, H., Okada, Y. and Nomura, M. (2009). Pharmacological activity of compounds extracted from persimmon peel (Diospyros kaki THUNB.). J. Oleo Sci., 58, 213-219.

Godevac, D., Tesević, V. and Vajs, V., Milosavljević, S. and Stanković, M. (2009). Antioxidant properties of raspberry seed extracts on micronucleus distribution in peripheral blood lymphocytes. Food Chem. Toxicol., 47, 2853-2859.

Gorinstein, S., Zemser, M., Weisz, M., Halevy, S., Deutsch, J., Tilus, K., Feintuch, D., Guerra, N., Fishman, M. and Bartnikowska, E. (1994). Fluorometric analysis of phenolics in persimmons. Biosci. Biotechnol. Biochem., 58, 1087-1092.
Gutfinger, T. (1981). Polyphenol in olive oils. J. Am. Oil Chem. Soc., 58, 996-998.

Gu, H.F., Li, C.M., Xu, Y.J., Hu, W.F., Chen, M.H. and Wan, Q.H. (2008). Structural features and antioxidant activity of tannin from persimmon pulp. Food Res. Int., 41, 208-217.

Hosotani, K., Kawahata, A., Koyama, K., Murakami, C., Yoshida, H., Yamaji, R., Inui, H. and Nakano, Y. (2004). Effect of carotenoids and ascorbic acid of Japanese persimmons on cellular lipid peroxidation in HepG2 cells. Biofactors, 21, 241-245.

Jang, I.C., Jo, E.K., Bae, M.S., Lee, H.J., Jeon, G.I., Park, E., Yuk, H.G., Ahn, G.H. and Lee, S.C. (2010). Antioxidant and antigenotoxic activities of different parts of persimmon (Diospyros kaki cv. Fuyu) fruit. J. Med. Plant Res., 4, 155-160.

Jayaprakasha, G.K., Singh, R.P. and Sakariah, K.K. (2001). Antioxidant activity of grape seed (Vitis vinifera) extracts on peroxidation models in vitro. Food Chem., 73, 285-290.

Jeong, S.M., Kim, S.Y., Kim, D.R., Jo, S.C., Nam, K.C., Ahn, D.U. and Lee, S.C. (2004). Effect of heat treatment on antioxidant activity of citrus peels. J. Agric. Food Chem., 52, 3389-3393.

Jung, S.T., Park, Y.S., Zachwieja, Z., Folta, M., Barton, H., Piotrowicz, J., Katrich, E., Trakhtenberg, S. and Gorinstein, S. (2005). Some essential phytochemicals and the antioxidant potential in fresh and dried persimmon. Int. J. Food Sci. Nutr., 56, 105-113.

Kaviarasan, S., Vijayalakshmi, K. and Anuradha, CV. (2004). Polyphenol-rich extract of fenugreek seeds protect erythrocytes from oxidative damage. Plant Foods Hum. Nutr., 59,143-147.

Lee, Y.A., Cho, E.J. and Yokozawa, T. (2008). Protective effect of persimmon (Diospyros kaki) peel proanthocyanidin against oxidative damage under $\mathrm{H}_{2} \mathrm{O}_{2}$-induced cellular senescence. Biol. Pharm. Bull., 31, 1265-1269.

Lee, Y.M. and Kim, C.C. (1994). Studies on the fatty acid composition of sweet persimmons (Diospyros kaki L.). J. Kor. Soc. Hort. Sci., 35, 233-240.

Macheix, J.J., Fleuriet, A. and Billot, J. (1990). "Fruit phenolics." CRC Press, Inc., Florida, USA.

Meir, S., Kanner, J., Akiri, B. and Hadas, S.P. (1995). Determination and involvement of aqueous reducing compounds in oxidative defense systems of various senescing leaves. J. Agric. Food Chem., 43, 1813-1817.

Moon, K.D., Kim, J.K., Kim, J.H. and Oh, S.L. (1995). Studies on valuable components and processing of persimmon flesh and peel. Kor. J. Diet. Cult., 10, 321-326.

Muller, H.E. (1985). Detection of hydrogen peroxide produced by microorganism on ABTS-peroxidase medium. Zentralbl. Bakteriol. Mikrobiol. Hyg., 259, 151-158.

New Food Composition Table Editing Committee (2009). "New Food Composition Table.” Hitotsubashi Press Co., Tokyo, Japan

Nicoletta, P., Roberta, R., Min, Y. and Catherine, R.E. (1999). Screening of dietary carotenoids and carotenoid-rich fruit extracts for antioxidant activities applying 2,2'-azinobis (3-ethylbenzo- 
thiazoline-6-sulfonic acid) radical cation decolorization assay. Methods Enzymol., 299, 379-389.

Orhan, I. and Sener, B. (2002). Fatty acid content of selected seed oils. J. Herb. Pharmacother, 2, 29-33.

Oyaizu, M. (1986). Antiangiogenic properties of natural polyphenols from red wine and green tea. Jap. J. Nut., 44, 307-315.

Richard, D., Kefi, K., Barbe, U., Bausero, P. and Visioli, F. (2008). Polyunsaturated fatty acids as antioxidants. Pharmacol. Res., 57, 451-455

Steinmetz, K.A. and Potter, J.D. (1996). Vegetables, fruit, and cancer prevention: a review. J. Am. Diet. Assoc., 53, 536-543.
Suzuki, T., Someya, S., Hu, F. and Tanokura, M. (2005). Comparative study of catechin compositions in five Japanese persimmons (Diospyros kaki). Food Chem., 93, 149-152.

Tsurunaga, Y., Matsumoto, T., Kurahashi, T., Mochida, K., Suzuki, Y., and Itamura, H. (2008). Functional component contents in mature leaves, young shoots, and adventitious shoots of Japanese persimmon 'Saijo'. Food Sci. Technol. Res., 14, 62-66.

Veberic, R., Jurhar, J., Mikulic-Petkovsek, M., Stampar, F. and Schmitzer, V. (2010). Comparative study of primary and secondary metabolites in 11 cultivars of persimmon fruit (Diospyros kaki L.). Food Chem., 119, 477-483. 